\title{
EFFECT OF HIGH TONE POWER THERAPY ON NEUROLOGICAL SYMPTOMS AND FUNCTION OUTCOME IN PATIENTS WITH DIABETIC NEUROPATHY.
}

\author{
Walid K. M. Abo El-Regal* ; Hany E. Obaya*; Emad M. Taha*
} And Khaled L.A. Hawaas**

*Faculty of Physical Therapy, Cairo University, Department of Physical Therapy For Cardiovascular/Respiratory Disorder and Geriatrics.

**Farskoor Public Hospital, Ministry of Health.

Key Words: High tone power therapy, Neurological symptoms, Function outcomes, Diabetic neuropathy, Katz Index of Independence, Glyclated Haemoglobin Level (HbA1c),

\section{ABSTRACT}

Background: High tone power therapy has an effect on neurological symptoms and function outcome in patients with diabetic neuropathy. The aim: This study aimed to identify the effect of high tone power therapy on neurological symptoms and function outcome in patients with diabetic neuropathy.Methods: Sixty patients diagnosed with diabetic neuropathy, Their age ranged from fifty to sixty years old from Farskoor Public Hospital in Damietta were involved in this study. They were assigned into 2 groups equal in numbers . thirty patients received treatment with high tone power therapy in addition to their traditional physical therapy program. The other thirty patients received only their traditional physical therapy program ( active free exercises for hip flexion,extention, adduction, abduction , knee flexion, extention and gait training). Before inclusion in this study full description of study, procedures for each patient and written consent had been signed. All patients were evaluated with Katz Index of Independence and measuring Glyclated Haemoglobin Level (HbA1c) .These evaluations are repeated again 3 monthes later at the end of the study. The results: Control group included 19 male with percentage of $63.33 \%$ and 11 female with percentage of $36.66 \%$, Study group included 18 male with percentage of $60 \%$ and 12 female with percentage of $40 \%$. The results showed that there were significant differences in the mean values at post-treatment of HbA1c percentage $(\mathrm{P}=0.036 ; \mathrm{P}<0.05)$ between study group and control group, Study group improved KATZ scale $(72.08 \%)$ than control group $(16.56 \%)$. Conclusion: High tone power therapy is effective in the treatment of neurological symptoms and increasing function outcome in patients with diabetic neuropathy. 


\section{INTRODUCTION}

Diabetes mellitus (DM) is a chronic, metabolic disease characterized by elevated levels of blood glucose (or blood sugar), which leads over time to serious damage to the heart, blood vessels, eyes, kidneys, and nerves. The most common is type 2 diabetes, usually in adults, which occurs when the body becomes resistant to insulin or does not make enough insulin (WHO, 2018).

Diabetic neuropathies (DNs) are nerve-damaging disorders associated with DM. These conditions are thought to result from diabetic microvascular injury involving small blood vessels that supply nerves (vasa nervorum) in addition to macrovascular conditions that can culminate in diabetic neuropathy (Behl., 2015).

Electrical stimulation (ES) produces skeletal muscle contractions as results of the percutaneous stimulation of peripheral nerves. (Hamada, Hayashi and Kimura, et al 2004). Transcutaneous electrical nerve stimulation (TENS), percutaneous electrical nerve stimulation, spinal cord stimulation, other physical therapies and acupuncture have also successfully been used as non-pharmacological therapies for neuropathic deficits in diabetic polyneuropathy (Leonard, et al 2004)., while electrical stimulation therapy through stocking electrodes was not effective (Oyibo, et al 2004).

High tone power therapy (HiTop) is a new quantum leap in the field of electro therapy. It is electrotherapy with sinusoidal alternating currents. The high tone power therapy provides a therapy with medium frequency sine waves. The therapy is free of direct current (D.C.) components. The amplitude and the frequency are modulated simultaneously. The higher the frequency, the more energy can be introduced corresponding to the individual threshold curve of the patient's electrosensitivity (Reichstein et al, 2005).

A short-term intervention over 5 days with HiTop has the potential to immediately reduce pain with a significantly stronger analgesic effect than TENS. Particularly, the first period of intervention showed that HTEMS reduces pain to a greater extent than TENS. From a clinical point of view, HTEMS showed a promising result, especially when comparing with TENS or considering the short period of intervention time. (Hawker, 2011).

\section{(I) Subject's selection:}

\section{SUBJECT AND METHODS}

Sixty patients diagnosed with diabetic neuropathy ranged from 50 to 60 years old from Farskoor Public Hospital in Damietta were involved in this study. 
Patients were assigned into two equal groups in number:

Group A : consisted of 30 type 2 diabetic patients with diabetic neuropathy and was received High tone power therapy for 30 minutes , in addition to selected physical therapy program (AROM exercises for LL, gentle manual stretching exercises for LL and graduated gait training)..

Group B : consisted of 30 type 2 diabetic patients with diabetic neuropathy and was received only their selected physical therapy program (AROM exercises for LL, gentle manual stretching exercises for LL and graduated gait training).

\section{Ethics Committee}

The study was approved by the Ethics Committee of the Faculty of Physical Therapy, Cairo University. A written informed consent was obtained from all the participants.

\section{Inclusion criteria:}

1. Sixty patients diagnosed with diabetic neuropathy from both genders their ages were ranged from 50-60 years old.

2. All patients in the study were ambulant independently.

3. All patients were under full medical control

4. HbA1c was ranged from $6.5: 7 \%$.

5. Patients had diabetes more than 10 years.

Exclusion criteria:

All patients were excluded from this study if they have:

6. Psychiatric disorders or seizures.

7. Visual and auditory impairment or tremors influencing balance.

8. Other neuromuscular disorders.

9. Foot deformities and ulcers.

10. Lower limb operations.

(III) Methods: (A- Instrumentations, B- Procedures):

(A) Instrumentations: (a- For evaluation, b- For treatment): a- For evaluation:

1. Measuring Glyclated Haemoglobin Level (HbA1c) before and after the intervention to detect effect of the intervention on blood glucose level.

2. Katz Index of Independence: was used to measure function outcome and ADL.

Validity and reliability of Katz Index of Independence:

Reliability was established with twelve subjects interviewed by one interviewer with the second-rater present but not participating in the interview process. Inter-rater reliability was established at .85. The 
validity of the Katz Index of Independence was tested by determining the correlation of the Katz Index of Independence with four scales that measured domains of functional status. The Physical Classification (6point rating of physical health), Mental Status Questionnaire (10-point test of orientation and memory), Behavior and Adjustment rating scales (4-6-point measure of intellectual, person, behavioral and social adjustment), and the PSMS (6-item ADLs). A total of 180 research subjects participated in the study, however, few received all five evaluations. All correlations were significant at the .01 or .05 level (Wallace and Shelkey., 2007).

\section{b- For treatment:}

1. High Tone Power Therapy (HiTop 191; gbo Medizintechnik, Rimbach, Germany).

(B) Procedures: (a- For evaluation, b- For treatment)

a- For evaluation (pre and post treatment program):

1. Measuring Glyclated Haemoglobin Level (HbA1c).

2. Katz Index of Independence: was used to measure function outcome and ADL.

Katz Index of Independence: the index ranks adequacy of performance in the six functions of bathing, dressing, toileting, transferring, continence, and feeding. Clients are scored yes/no for independence in each of the six functions. A score of $\mathbf{6}$ indicates full function, 4 indicates moderate impairment, and $\mathbf{2}$ or less indicates severe functional impairment.

b- For treatment:

All 60 referred patients were classified into two equal groups, each group will consist of 30 patients:

Group I (Study): Consisted of 30 patients with diabetic neuropathy and was received High tone power therapy and a traditional physical therapy program (AROM exercises for LL, gentle manual stretching exercises for LL and graduated gait training).

Group II (Control): Consisted of 30 patients with diabetic neuropathy and was received only a traditional physical therapy program (AROM exercises for LL, gentle manual stretching exercises for LL and graduated gait training).

2. High Tone Power Therapy (HiTop 191): (For group I).

The high tone power therapy through using a device (HiTop 191; gbo Medizintechnik, Rimbach, Germany).

\section{Statistical Analysis}

All statistical measurements have been carried out using the statistical package for social sciences version26 (SPSS Inc., Chicago, Illinois, USA). In this study, mean $\mathrm{SD} \pm$ was calculated for all measured 
variables. Descriptive statistics and t-test were used for comparing mean demographic data between both groups. Paired t-test was applied for comparing mean demographic data between both the groups. Paired t-test was applied for comparison within the same group. Independent t-teat was applied for comparison between both the groups before and after the intervention. A value of $\mathrm{P}$ less than 0.05 was considered statistically significant.

Prior for final analysis, data were screened, for normality assumption test by using Shapiro-Wilk test $(\mathrm{P}<0.05)$ and homogeneity of variance by Levene's test $(\mathrm{P}<0.05)$. The data was not normally distributed and nonparametric analysis. The statistical analysis was conducted by using statistical SPSS Package program version 25 for Windows (SPSS, Inc., Chicago, IL). All data are expressed as mean and standard deviation for Dermoscopy assessment and SCORAD scale assessment variables. Wilcoxon signed ranks test to compare within each group and using Mann-Whitney test to compare between two groups. All statistical analyses were significant at level of probability less than an equal $0.05(\mathrm{P}$ $\leq 0.05)$.

\section{RESULTS}

A total of 60 type II diabetic patients participated in this study; they were randomly distributed into 2 groups (30 patients/group). In control group, the number frequency (percentage) of gender distribution were 19 male $(63.33 \%)$ and 11 female $(36.66 \%)$ and in study group were 18 male $(60.00 \%)$ and 12 female $(40.00 \%)$. Comparing the general characteristics of the subjects of both groups (Table 1) revealed that no significant differences in age $(\mathrm{P}=0.482 ; \mathrm{P}>0.05)$, weight $(\mathrm{P}=0.561 ; \mathrm{P}>0.05)$, and height $(\mathrm{P}=0.834 ; \mathrm{P}>0.05)$ between control group and study group.

Table 1. Comparison mean values of demographic data between both groups.

\begin{tabular}{|l|l|l|l|}
\hline \multirow{2}{*}{ Variables } & Groups $($ Mean \pm SD) & \multirow{2}{*}{ P-value } \\
\cline { 2 - 3 } & Control group $(\mathbf{n}=30)$ & Study group $(\mathrm{n}=30)$ & $\mathbf{0 . 4 8 2}$ \\
\hline Age $($ Year$)$ & $\mathbf{5 5 . 1 3} \pm \mathbf{2 . 9 3}$ & $\mathbf{5 5 . 6 6} \pm \mathbf{2 . 9 0}$ & $\mathbf{0 . 5 6 1}$ \\
\hline Weight $(\mathrm{kg})$ & $\mathbf{8 2 . 9 6} \pm \mathbf{7 . 8 9}$ & $\mathbf{8 4 . 3 0} \pm 9.68$ & $\mathbf{0 . 8 3 4}$ \\
\hline Height $(\mathrm{cm})$ & $\mathbf{1 6 9 . 8 3} \pm 9.09$ & $\mathbf{1 6 9 . 3} \pm 9.34$ & \\
\hline
\end{tabular}

Data are expressed as mean \pm standard deviation (SD)

P-value: probability value

The statistical analysis within each group (Table 2 and Figure 1) revealed that there were significant difference in HbAlc percentage $(\mathrm{P}=0.002 ; \mathrm{P}<0.05)$ when comparing the pre-treatment mean values with post-treatment mean values. Moreover, study group improved HbA1c percentage $(7.03 \%)$ than control group $(8.77 \%)$. 
The statistical analysis between study group and control group (Table 2 and Figure 1) showed no significant differences in mean values at pre-treatment of $\mathrm{HbA} 1 \mathrm{c}$ percentage $(\mathrm{P}=0.907 ; \mathrm{P}>0.05)$. However, there were significant differences in the mean values at post-treatment of HbA1c percentage $(\mathrm{P}=0.036 ; \mathrm{P}<0.05)$ between study group and control group.

Table 2: Comparison of HbA1c \% variables within and between two groups.

\begin{tabular}{|c|c|c|c|c|}
\hline \multirow{2}{*}{ Variables } & & \multicolumn{2}{|l|}{ Groups (Mean \pm SD) } & \multirow{2}{*}{$\begin{array}{r}P- \\
\text { value }\end{array}$} \\
\hline & & Control group $(n=30)$ & Study group $(n=30)$ & \\
\hline \multirow{5}{*}{ HbA1c \% } & Pre-treatment & $6.73 \pm 0.15$ & $6.83 \pm 0.16$ & 0.907 \\
\hline & Post-treatment & $6.14 \pm 0.38$ & $6.35 \pm 0.36$ & $0.036{ }^{*}$ \\
\hline & Change & 0.006 & 0.005 & \\
\hline & Improvement \% & $8.77 \%$ & $7.03 \%$ & \\
\hline & $P$-value & $0.001^{*}$ & $0.0001^{*}$ & \\
\hline
\end{tabular}

Data are expressed as mean \pm standard deviation $(\mathrm{SD})$

P-value: probability value $\quad$ "Significant $(\mathrm{P}<0.05)$

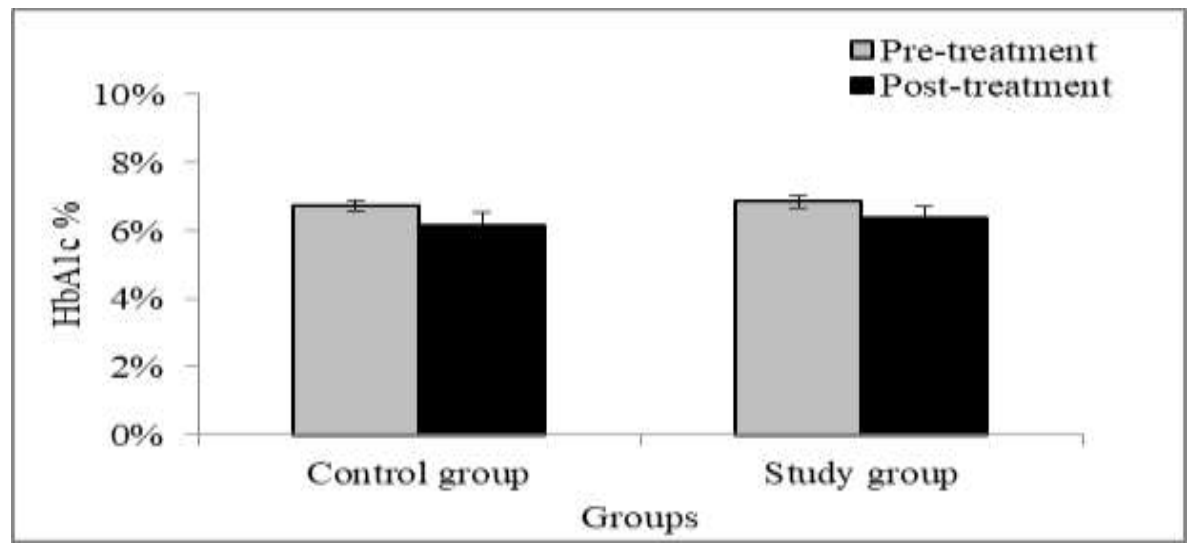

Figure 1: Mean values of pre- and post-treatment of HbA1c \% in study and control groups.

The statistical analysis within each group (Table 3 and Figure 2) revealed that there were significant difference in KATZ scale $(\mathrm{P}=0.001$; $\mathrm{P}<0.05)$ when comparing the pre-treatment mean values with posttreatment mean values. Moreover, study group improved KATZ scale $(72.08 \%)$ than control group $(16.56 \%)$.

The statistical analysis between study group and control group (Table 3 and Figure 2) showed no significant differences in mean values at pre-treatment KATZ scale $(\mathrm{P}=0.665 ; \mathrm{P}>0.05)$. Moreover, no significant differences in the mean values at post-treatment of KATZ scale $(\mathrm{P}=0.587 ; \mathrm{P}>0.05)$ between study group and control group. 
Table 3: Comparison of KATZ scale variables within and between two groups.

\begin{tabular}{|c|c|c|c|c|}
\hline \multirow{2}{*}{ Variables } & & \multicolumn{2}{|l|}{ Groups (Mean \pm SD) } & \multirow{2}{*}{$\begin{array}{r}P- \\
\text { value }\end{array}$} \\
\hline & & Control group $(n=30)$ & Study group $(n=30)$ & \\
\hline \multirow{5}{*}{ KATZ scale } & Pre-treatment & $3.20 \pm 0.80$ & $2.40 \pm 0.81$ & 0.665 \\
\hline & Post-treatment & $3.73 \pm 0.86$ & $4.13 \pm 0.50$ & 0.587 \\
\hline & Change & 0.53 & 1.73 & \\
\hline & Improvement \% & $16.56 \%$ & $72.08 \%$ & \\
\hline & $P$-value & $0.001^{*}$ & $0.0001^{*}$ & \\
\hline
\end{tabular}

Data are expressed as mean \pm standard deviation (SD)

P-value: probability value $\quad$ * Significant $(\mathrm{P}<0.05)$

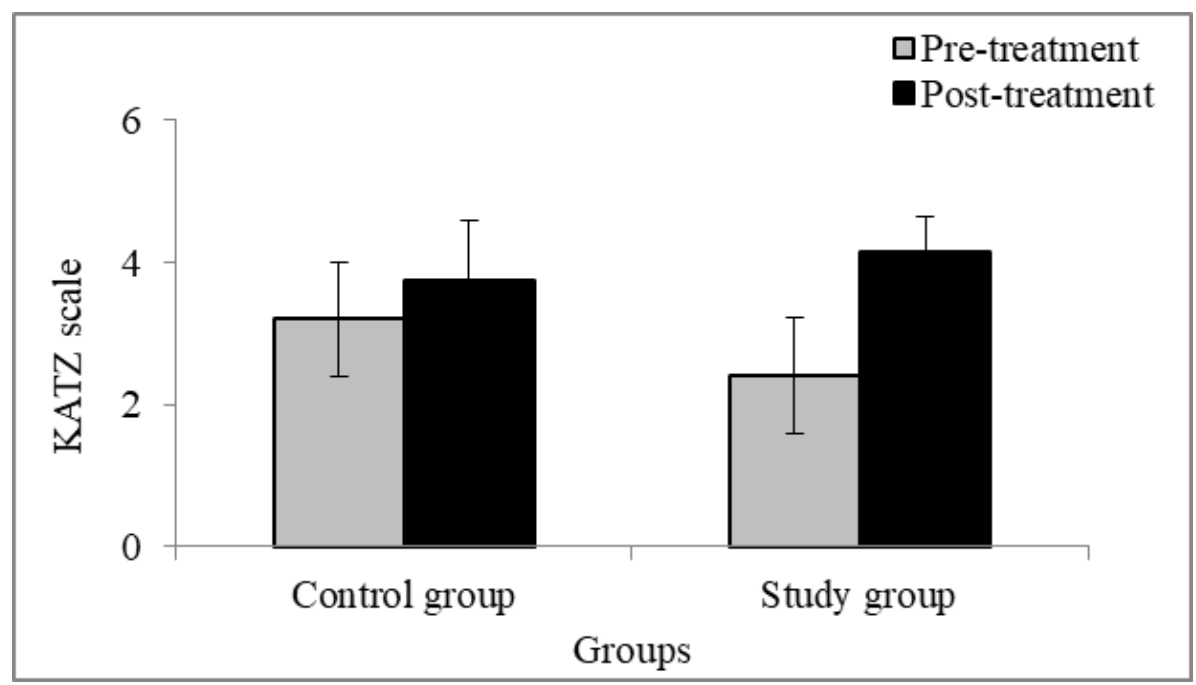

Figure 2: Mean values of pre- and post-treatment of KATZ scale in study and control groups.

\section{DISCUSSION}

This study aimed to identify the effect of high tone power therapy on neurological symptoms and function outcome in patients with diabetic neuropathy.

Sixty patients diagnosed with diabetic neuropathy ranged from 50 to 60 years old from different hospitals and out-patient clinics of internal medicine and neurology in Damietta were involved in this study. Before inclusion in this study full description of study, procedures for each patient and written consent had been signed. Subjects included in the study had the following criteria: should be ambulant independently, should be under full medical control, HbA1c was ranged from 6.5: $7 \%$, had diabetes more than 10 years. All patients were evaluated with diabetic neuropathy from both genders. 
The findings of the study showed that: Control group included 19 male with percentage of $63.33 \%$ and 11 female with percentage of $36.66 \%$, Study group included 18 male with percentage of $60 \%$ and 12 female with percentage of $40 \%$. The results showed that there were significant differences in the mean values at post-treatment of $\mathrm{HbA} 1 \mathrm{c}$ percentage $(\mathrm{P}=0.036 ; \mathrm{P}<0.05)$ between study group and control group. Study group improved KATZ scale $(72.08 \%)$ than control group (16.56\%). Moreover, no significant differences in the mean values at post-treatment of KATZ scale $(\mathrm{P}=0.587 ; \mathrm{P}>0.05)$ between study group and control group.

Watkins and Koeze, 1993 reported that high-frequency electrical spinal cord stimulation with implanted electrodes has been shown to be effective in the relief of chronic diabetic neuropathic pain, As they used special stimulation system (HiTop 181-H) for external muscle contraction. They applied 1-s frequencies of $4,096-32,768 \mathrm{~Hz}$, introducing up to $5,000 \mathrm{~mW}$ into the muscles. Mima et. al., 2004 reported that high-frequency electrical spinal cord stimulation is effective in the treatment of several other chronic painful conditions, including back pain, phantom-limb pain, peripheral vascular disease and severe angina

Tesfaye et al., 1992 had proposed that electrical stimulation activates the dorsal columns that inhibit the C fibres, thus interrupting/ gating pain input. Furthermore, Tesfaye et al., 1993 reported that shortterm high-frequency electrical nerve stimulation decreases human motor cortex excitability.

The study of Kerstin et al., 2018 demonstrated that a short-term intervention over 5 days with HTEMS has the potential to immediately reduce sciatic pain with a significantly stronger analgesic effect than TENS in middle-aged patients with chronic sciatica.

Although the exact mechanisms are unknown, so far it was postulated that HTEMS enhances the release of endogenous analgesics (Robinson A., 2008). Additionally, it increases vasodilatation (enhanced bioavailability of nitric oxide) leading to improved microcirculation and endoneural blood flow (locally and systemically) (Di et al., 2014). Another important assumption is that the application of neuromuscular electrical stimulation improves muscle strength contributing to an improved state of motor control of the spine as it was also shown after motor control exercise (Saragiotto et al., 2016) and (Di et al., 2014). 
Experiments indicated that electrical stimulation was followed by a decrease in the concentrations of the excitatory amino acids glutamate and aspartate in the dorsal horn, and that this effect is mediated by a GABAergic mechanism and microvascular changes, reduced blood flow, nerve oxygen tension (Stevens et al., 1995) contribute to the pathogenesis of diabetic neuropathy. Interestingly, electrical stimulation has been reported to improve microvascular blood flow in severe limb ischemia (Jacobs et al., 1988), effects on wound healing (indicating improved tissue circulation (Baker et al., 1997) and improve insulin resistance (Hamada et al., 2004).

L. Reichstein et al., 2005 founded that HF is a useful non-invasive, non-pharmacological treatment for the management of peripheral polyneuropathy in patients with diabetes.

\section{CONCLUSION}

On the basis of the study, It was concluded that high tone power therapy has an effect on neurological symptoms and function outcome in patients with diabetic neuropathy.

\section{REFERENCES}

Baker, L.L. ; R. Chambers; S.K. DeMuth and F. Villar (1997): Effects of electrical stimulation on wound healing in patients with diabetic ulcers. Diabetes Care., 20:405-412.

Behl, T. (2015): "Implication of oxidative stress in progression of diabetic retinopathy. Surv Ophthalmol. 2015.

Di Iorio, B. ; S. Marzocco ; L. Di Micco, et al., (2014): High-tone external muscle stimulation in patients with acute kidney injury (AKI): Beneficial effects on NO metabolism, asymmetric dimethylarginine, and endothelin-1. Clin Nephrol; 82(5): 304-12.

Hamada, T. ; T. Hayashi ; T. Kimura ; K. Nakao and T. Moritani (2004): Electrical stimulation of human lower extremities enhances energy consumption, carbohydrate oxidation, and whole body glucose uptake. J Appl Physiol, 96:911-916.

Hamada, T. ; T. Hayashi ; T. Kimura ; K. Nakao and T. Moritani (2004): Electrical stimulation of human lower extremities enhances energy consumption, carbohydrate oxidation, and whole body glucose uptake. J. Appl. Physiol., 96:911-916.

Hawker, G.A. ; S. Mian and T. Kendzerska (2011): Measures of adult pain: Visual Analog Scale for pain (VAS Pain), Numeric Rating Scale for pain (NRS Pain), McGill Pain Questionnaire (MPQ), Short-Form McGill Pain Questionnaire (SF-MPQ), Chronic Pain Grade Scale (CPGS), Short Form-36 Bodily Pain Scale (SF-36 BPS), and Measure of Intermittent and Constant Osteoarthritis 
Pain (ICOAP). Arthritis Care Res (Hoboken; 63(Suppl. 11): S240-52.)

Jacobs, M.J. ; P.J. Jorning ; S.R. Joshi et al., (1988): Epidural spinal cord electrical stimulation improves microvascular blood flow in severe limb ischemia. Ann Surg., 207:179-183.

Kerstin Kempf ; Martin Röhling ; Eslam Darwish ; Stephan Martin ; Sebastian Jander ; Jörg Herdmann and Susanne StehrZirngibl (2018): High-Tone External Muscle Stimulation for the Treatment of Chronic Sciatica - A Randomized Controlled Crossover Trial. The Open Pain Journal. , 11: 1-11.

Leonard, D.R. ; M.H. Farooqi and S. Myers (2004): Restoration of sensation, reduced pain, and improved balance in subjects with diabetic peripheral neuropathy: a double-blind, randomized, placebo-controlled study with monochromatic near-infrared treatment. Diabetes Care, 27:168-172.

Mima, T. ; T.Oga ; J. Rothwell et al.,(2004): Short-term highfrequency transcutaneous electrical nerve stimulation decreases human motor cortex excitability. Neurosci Lett., 355:85-88 24.

North, R.B. ; D.H. Kidd ; M Zahurak, C.S. James and D.M. Long (1993): Spinal cord stimulation for chronic, intractable pain: experience over two decades. Neurosurgery, 32:384-394 20.

Oyibo, S.O. ; K. Breislin and A.J. Boulton (2004): Electrical stimulation therapy through stocking electrodes for painful diabetic neuropathy: a double blind, controlled crossover study. Diabet Med., 21:940-944.

Reichstein, L. ; S. Labrenz ; D. Ziegler and S. Martin (2005): Effective treatment of symptomatic diabetic polyneuropathy by high-frequency external muscle stimulation. PMID., 48(5):824-8

Reichstein, L. ; S. Labrenz ; D. Ziegler and S. Martin (2005): Effective treatment of symptomatic diabetic polyneuropathy by high-frequency external muscle stimulation. Diabetologia ; 48 : $824-828$.

Robinson, A.J. (2008): Clinical electrophysiology: Electrotherapy and electrophysiologic testing. Baltimore: Lippincott Williams and Wilkins.

Saragiotto, B.T. ; C.G. Maher ; T.P. Yamato et al. (2016): Motor control exercise for chronic non-specific low-back pain. Cochrane Database Syst Rev,(1): CD012004.

Stevens, M.J. ; E.L. Feldman and D.A. Greene (1995): The aetiology of diabetic neuropathy: the combined roles of metabolic and vascular defects. Diabet Med, 12:566-579.

TenVaarwerk, I.A. ; G.A. Jessurun; M.J. DeJongste et al.,(1999): Clinical outcome of patients treated with spinal cord stimulation 
for therapeutically refractory angina pectoris. The Working Group on Neurocardiology. Heart, 82:82-88.

Tesfaye, S. ; J. Watt ; S.J. Benbow et al., (1996): Electrical spinal-cord stimulation for painful diabetic peripheral neuropathy. Lancet, 348:1698-1701.

Tesfaye, S. ; N. Harris ; J.J. Jakubowski et al.,(1993): Impaired blood flow and arterio-venous shunting in human diabetic neuropathy: a novel technique of nerve photography and fluorescein angiography. Diabetologia, 36:1266-1274.

Tesfaye, S. ; N.D. Harris ; R.M. Wilson and J.D. Ward (1992): Exerciseinduced conduction velocity increment: a marker of impaired peripheral nerve blood flow in diabetic neuropathy. Diabetologia, 35:155-159 26.

Wallace, M. and M. Shelkey (2007): Katz Index of Independence in Activities of Daily Living.

Watkins, E.S. and T.H. Koeze (1993): Spinal cord stimulation and pain relief. BMJ., 307:462.

WHO, World Health Organization (2018): family and diabetes; 14 November. 2018.

تأثير العلاج بجهاز التردد العالي علي الأعراض العصبية والوظيفية في حالات

$$
\text { وليد خالد محمود أبو الرجال * ، هاب الأعصاب الطرفية لمرضي السكر. }
$$

* كلية العلاج الطبيعي جامعة القاهرة قسم العلاج الطبيعي لأمراض القلب والأوعية الدموية / الجهاز التتفسي

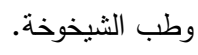
* * مستشفى فارسكور العام بوزارة الصحة.

هدفت هذه الدراسة إلى تحديد نأثير العلاج بجهاز التردد العالئ العالي علي الأعراض العصبية

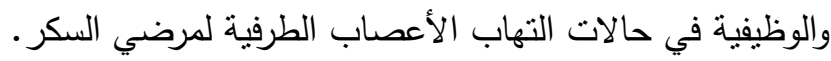

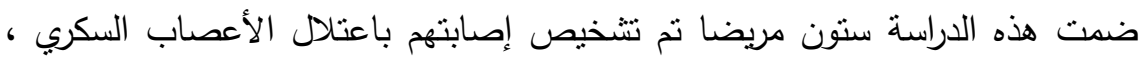

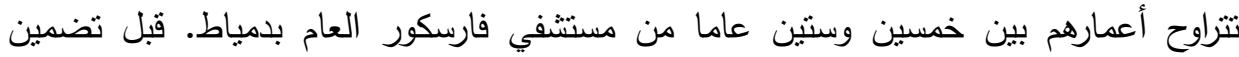

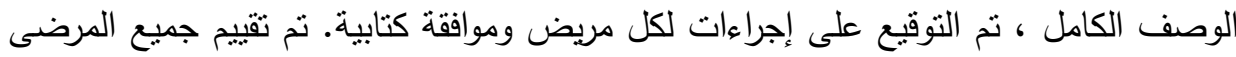
من خلال قياس مستوى الهيموجلوبين السكري (HbA1c) و مؤشر كاتز للاستقلالية.

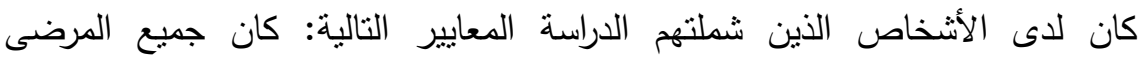
بسنطيعون الحركة بشكل مستقل بمفردهم. حالتهم الطبية مسنقرة:ثراوح مستوى الهيموجلوبين

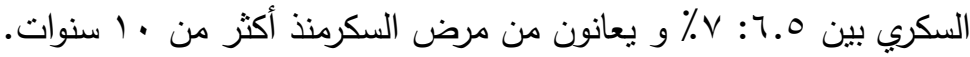


تم استبعاد جميع المرضى الذين يعانون من: الاضطرابات النفسية أو النوبات؛ ضعف

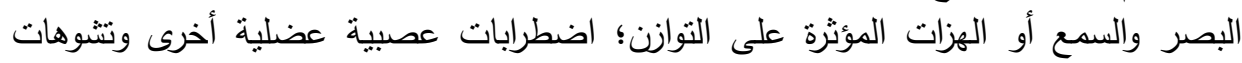
وتقرحات القدم و عمليات الأطراف السفلية. تم تقسيم الستين مريض الي مجموعنين منساوينين في العدد. تلقت المجاف العموعة الاولي العلاج بجهاز التردد العالي بالاضافة الي برنامج العلاج الطبيعي ( التدرب علي المشي، تلفين تمارين

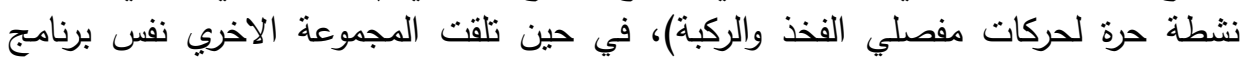
العلاج الطبيعي فقط.

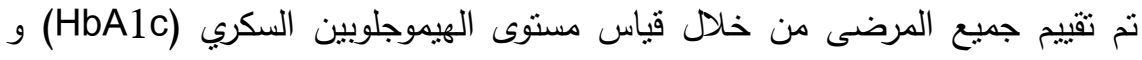
مؤشر كاتز للاستقالية وذلك قبل بداية الدراسة واعادتها مرة اخري بعد ثلاثة اشهر عقب الثب انتهاء الدراسة.

في نهاية الدراسة وجد أن العلاج بجهاز التردد العالي يحسن من الأعراض العصبية

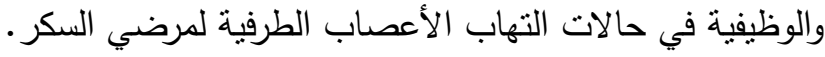

